\title{
Lifitegrast Ophthalmic Solution $5.0 \%$ for Treatment of Dry Eye Disease: Overview of Clinical Trial Program
}

\author{
Clara C. Chan, ${ }^{1}$ C. Lisa Prokopich ${ }^{2}$ \\ ${ }^{1}$ Department of Ophthalmology \& Vision Sciences, University of Toronto, Toronto, ON, Canada; ${ }^{2}$ Optometry and Vision \\ Science, University of Waterloo, Waterloo, ON, Canada.
}

Received, October 12, 2018; Accepted, January 7, 2019; Published, January 9, 2019.

\begin{abstract}
Dry eye disease (DED) is a common inflammatory disorder of the ocular surface. Millions of people are affected by DED worldwide. Lifitegrast is a novel drug designed to inhibit DED-associated ocular inflammation. Four clinical trials have shown that lifitegrast is well tolerated and effective in improving symptoms and signs of DED over 12 weeks. A fifth trial showed long-term safety over 1 year. Lifitegrast has been in clinical use for more than one year in the United States and was recently approved in Canada (in December 2017). In this review, we discuss lifitegrast's novel mechanism of action and provide an overview of its clinical trial program.
\end{abstract}

\section{DRY EYE DISEASE}

Dry eye disease (DED) is a highly prevalent, multifactorial eye disease that affects the ocular surface and tear film (1). It is characterized by tear film instability and tear hyperosmolarity (1). Tears protect and lubricate the ocular surface, and provide a clear refractive medium for light to enter the eye. In DED, the eye does not produce an adequate amount of tears and/or produces poor-quality tears, resulting in ocular surface damage and inflammation. The impact of DED cannot be overlooked; a 2006 study concluded that the effect of DED on patient-reported health states ranked similarly to diseases such as angina and the need for dialysis $(2,3)$.

Common symptoms of DED include eye dryness, ocular pain and discomfort, and visual disturbances (1). DED negatively impacts vision, reduces health-related quality of life, and imposes a considerable economic burden on patients (4).

Previous research shows that DED is a highly prevalent disease that disproportionately affects older adults (aged $>50$ years) and women (4). The Dry Eye Workshop (DEWS) II report estimated that DED prevalence ranges globally from $5-50 \%$, though a number of studies estimate prevalence in the $20-30 \%$ range, particularly among those $>50$ years of age (4). The DEWS II meta-analysis confirmed previous findings that prevalence increases with age and is generally higher among women than men (4). In the 1997 Canada Dry Eye Epidemiology Study (CANDEES), 28.7\% of surveyed patients in optometric practices reported dry eye symptoms (5). A more recent survey by Caffery et al. estimates that $21.3 \%$ or $\sim 6.3$ million Canadians aged $\geq 18$ years, have DED (6). Given its high prevalence and negative impact on quality of life, and its symptomatic and chronic nature $(1,4,7)$, increasing numbers of patients will be presenting to health care providers for management of their DED symptoms.

Current treatment modalities that are available in Canada include ocular lubricants (preserved or preservative free), environmental modifications, anti-inflammatory treatments (short-term corticosteroid drops, immunomodulatory drops, oral omega-3 fatty acid supplements), tear conservation (lacrimal occlusion), and eyelid treatments (meibomian gland expression, doxycycline treatment, others) (8-10). Less commonly used interventions, prescribed in more severe cases, include scleral contact lenses, biological tear substitutes, tear stimulation, amniotic membranes, tarsorrhaphy, and systemic treatments such as immunosuppressants and tear secretagogues $(9,10)$. Most treatments focus on restoring tear film homeostasis, with very few therapies addressing the underlying inflammation, as discussed in the next section.

Corresponding Author: Clara C. Chan, MD, Department of Ophthalmology \& Vision Sciences, University of Toronto 601600 Sherbourne St, Toronto, ON M4X 1W4, Canada, Email: clarachanmd@gmail.com 
Here it is important to note that there is also growing clinical perception that some cases of DED may represent neuropathic pain that is the result of dysfunctional corneal neural feedback $(11,12)$. Such patients would typically present with severe symptoms of DED, particularly ocular pain, but little to no signs of ocular surface damage (11). Treatments directed towards the tear film would have limited impact on neuropathic pain. In such cases, neuropathic pain interventions, including treatments that have been traditionally used to manage pain, may be investigated $(11,12)$.

Clinical observations and impressions suggest that DED may be a progressive disorder. Lienert et al. reported worsening of DED symptoms over time (13) and Rao et al. have reported DED progression (worsening of signs and symptoms) in a proportion of patients (14). The DEWS II definition of DED does not include progression. However, the pathophysiological model of DED proposed by the DEWS II includes progressive inflammation and increasing tear hyperosmolarity and tear film instability (7). The DED management algorithm proposed by DEWS II also anticipates progression in disease severity (10).

Lifitegrast is a novel drug that was approved for the treatment of signs and symptoms of DED in adult patients, both by the US Food and Drug Administration (July 2016) (15) and by Health Canada (December 2017).

Typical T-Cell Activation

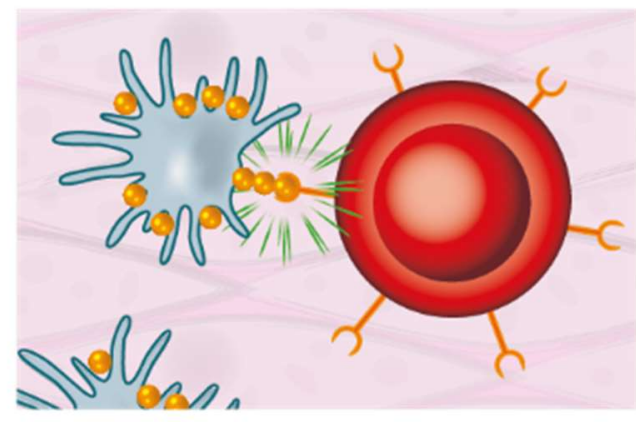

WHAT IS LIFITEGRAST AND HOW DOES IT WORK?

Lifitegrast is a small molecule immunomodulator designed to inhibit DED-associated ocular inflammation, thereby improving both signs and symptoms of DED. It has been developed specifically for ophthalmic use.

Ocular surface inflammation is widely understood to play a key role in the pathogenesis of DED (7). Desiccating stress on the ocular surface, and the resultant tear film hyperosmolarity, instability, and friction can damage the ocular surface and initiate a cascade of inflammatory events generating ocular immune responses (7). The initial innate immune response to surface damage is nonspecific and localized to the ocular surface. It triggers an acute inflammatory response that precedes the more specific adaptive immune response. In the adaptive response phase, antigenspecific memory and effector $\mathrm{T}$ cells are generated in the lymph nodes, from which they migrate to the ocular surface. In DED, amplified activation of these $\mathrm{T}$ cells causes further ocular surface damage and reactivation of the innate inflammatory response through release of inflammatory cytokines, leading to a cycle of chronic ocular surface damage and disease perpetuation (7).

A key step in the migration and activation of $\mathrm{T}$ cells is the binding of the lymphocyte functionassociated antigen 1 (LFA-1) with the intercellular adhesion molecule 1 (ICAM-1) (16).

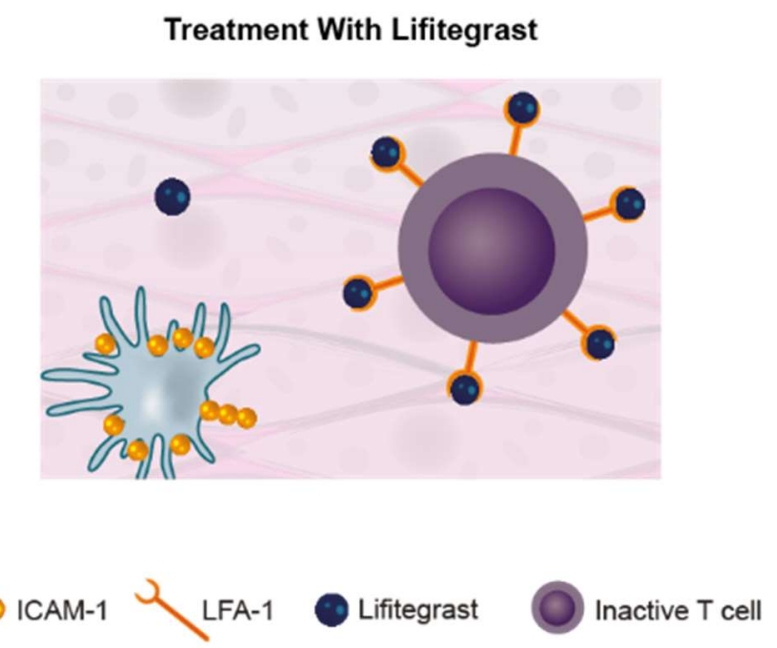

Figure 1. Lifitegrast blocks ICAM-1/LFA-1 interaction, inhibiting T-cell-mediated inflammation in dry eye disease. ICAM-1, intercellular adhesion molecule 1; LFA-1, lymphocyte function-associated antigen 1; mAPC, mature antigenpresenting cell. Adapted from Perez VL, et al. Lifitegrast, a novel integrin antagonist for treatment of dry eye disease. Ocul Surf, 2016; 14:207-215 DOI: 10.1016/j.jtos.2016.01.001 (17). Licensed under CC BY-NC-ND 4.0 (https://creativecommons.org/licenses/by-nc-nd/4.0). 
LFA-1 is an integrin that is expressed on the cell surface of leukocytes and helps modulate T-cell activation and proliferation. ICAM-1 is expressed on the surface of a variety of antigen-presenting cells and is upregulated during inflammation. LFA-1 binding to ICAM-1 promotes T-cell differentiation and migration to the ocular surface, as well as activation of $T$ cells on the ocular surface $(7,17)$. Lifitegrast is an LFA-1 antagonist. It interrupts the cycle of DED by blocking the binding of LFA-1 to ICAM-1 (Figure 1) $(16,17)$.

Other immunomodulators have also been shown to be effective in ameliorating DED. Cyclosporine, for example, inhibits activation of lymphocytes, which is mediated by interleukin 2 (IL-2). Topical ophthalmic cyclosporine $0.05 \%$ has been shown to reduce inflammatory markers and improve tear production in DED (10).

\section{HOW IS LIFITEGRAST USED?}

Anti-inflammatory treatment is most effective when applied directly to the affected site, that is, the ocular surface. Lifitegrast is available as a preservative-free $5.0 \%$ ophthalmic solution, administered 1 drop in each eye, twice daily. It has been studied in adults ( $\geq 18$ years of age) with DED, the demographic most likely to be affected.
The ocular distribution and pharmacokinetic profile of lifitegrast has been studied in pigmented rabbits. Following twice-daily ocular administration of lifitegrast for 5 days, lifitegrast distributed with the highest concentration in the anterior ocular segment tissues of the rabbit eye (Figure 2), and lower concentrations were observed in the posterior segment tissues and plasma. This suggests that lifitegrast would distribute to the appropriate target tissues for DED treatment, and would have low probability for off-target immune suppressant effects (18). Studies with ${ }^{14} \mathrm{C}$ lifitegrast in beagle dogs (administered as an ocular or intravenous dose) show that the drug is excreted as mainly unchanged lifitegrast, suggesting that it undergoes minimal metabolism in vivo (18). Results of pharmacokinetic experiments in rats showed that there is low systemic exposure (area under the concentration curve, $705 \mathrm{~h} \cdot \mathrm{ng} / \mathrm{kg}$ ) and rapid clearance of lifitegrast from systemic circulation (half-life, $\mathrm{t}_{1 / 2}=0.78 \mathrm{~h}$; clearance rate, $139.2 \mathrm{~mL} / \mathrm{min} / \mathrm{kg}$ ) (19). This was further confirmed in a phase 1 study, among healthy human subjects, where low plasma levels and rapid clearance within $1-4 \mathrm{~h}$ of ocular administration were observed (20).

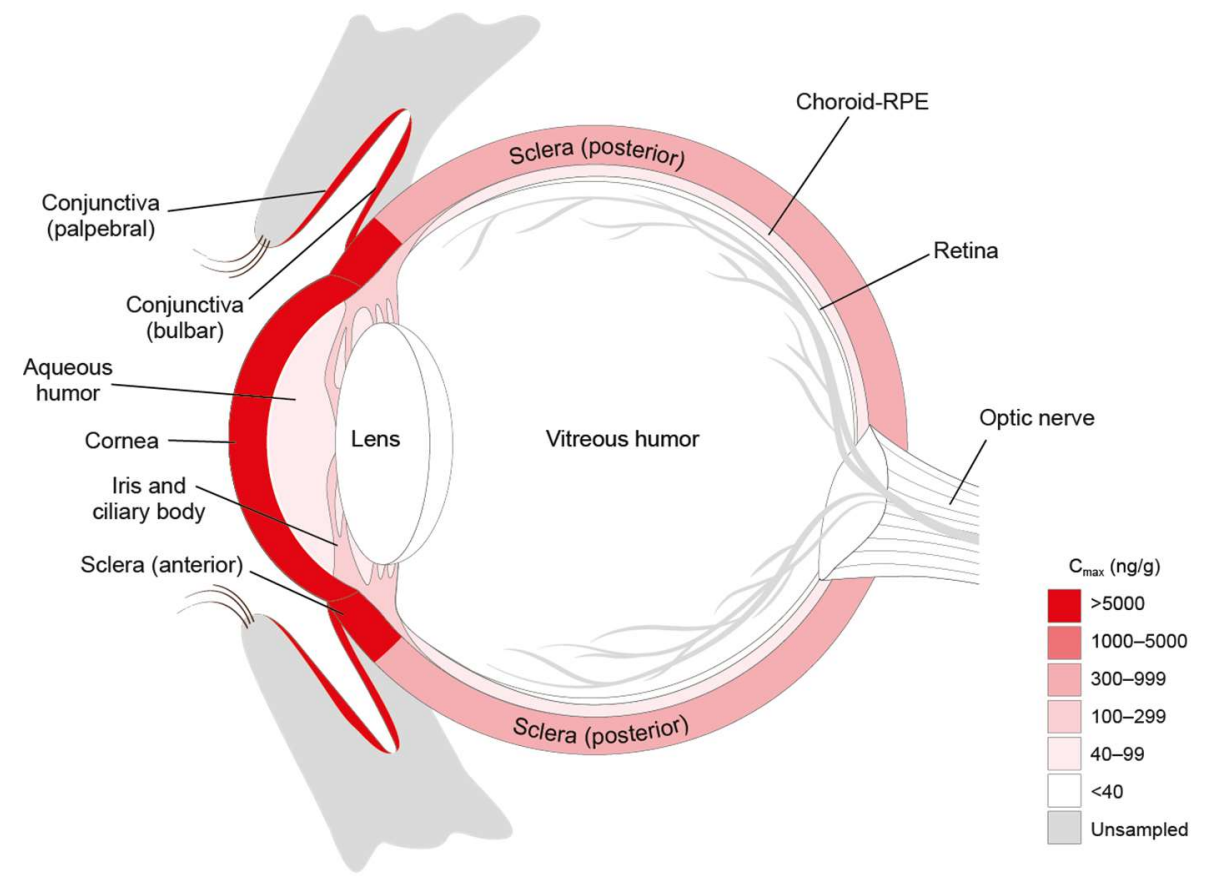

Figure. 2. Lifitegrast ophthalmic solution $5.0 \%$ distributes with high concentration in the anterior ocular segment of rabbit eyes after repeated topical application. $C_{\max }$, maximum concentration. Image reproduced from Chung JK, Spencer E, Hunt M, McCauley T, Welty D. Ocular distribution and pharmacokinetics of lifitegrast in pigmented rabbits and mass balance in beagle dogs. J Ocul Pharmacol Ther, 2018; 34:224-232, DOI: 10.1089/jop.2017.0106 (18). Licensed under CC BY 4.0 (https://creativecommons.org/licenses/by/4.0/). 


\section{WHAT IS THE EVIDENCE SO FAR FOR THE EFFICACY AND SAFETY OF LIFITEGRAST IN DED?}

The efficacy and safety of lifitegrast ophthalmic solution $5.0 \%$ were evaluated in four 84-day randomized placebo-controlled trials in patients with DED: 1 phase 2 trial (21) and three phase 3 trials: OPUS-1 (22), OPUS-2 (23), and OPUS-3 (24). Long-term safety and tolerability of lifitegrast vs. placebo were evaluated in patients with DED in a 1-year safety study (SONATA) (25). More than 2400 adults participated in these trials, and lifitegrast significantly improved symptoms and signs of DED vs. placebo. As in previous DED literature (26), significant improvement in both sign and symptom endpoints were not observed in the same trial. US Food and Drug Administration approval of lifitegrast for signs and symptoms of DED was based on results of multiple trials. Long-term efficacy of lifitegrast has not been assessed, as all 4 efficacy and safety trials were limited to 12 weeks; however, some 52-week data emerged from the SONATA safety study.

All studies were conducted in adults (aged 18-97 years) with DED. Enrolled participants were evaluated for DED signs and symptoms to confirm a diagnosis of DED at baseline. In addition, participants in the phase 2 and OPUS- 1 trials were also screened using a controlled adverse

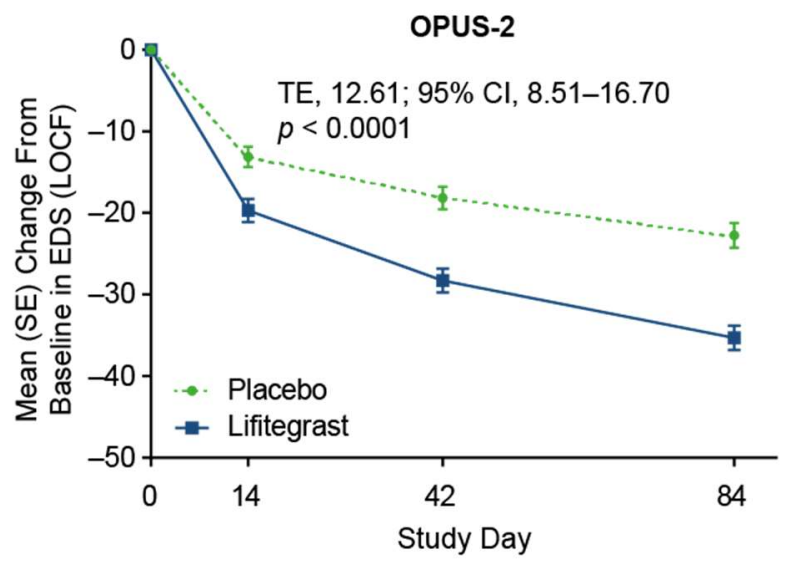

environment (CAE) $(21,22)$. In the CAE chamber, participants were exposed to acute environmental stress for 90 min under controlled conditions (visual tasking under ambient lighting, standardized temperature, humidity, and air flow). Only those who exhibited worsening of their DED signs and symptoms after exposure to CAE were included in the study. This helped identify patients with modifiable DED, while also helping to minimize variability due to external factors that may otherwise confound DED evaluation.

Efficacy of lifitegrast was evaluated against placebo (ophthalmic solution with all components of investigational product, except lifitegrast) in the four 12-week trials. In 2 trials, symptoms of eye dryness (as assessed by the eye dryness score [EDS], visual analog scale [VAS]) significantly improved with lifitegrast vs. placebo (Figure 3) $(23,24)$. Patients reported improvement with lifitegrast as early as day 14 (15). In a post hoc responder analysis, data from OPUS- 2 and OPUS- 3 were analyzed to assess the proportion of participants who achieved an EDS reduction from baseline ( $\geq 10, \geq 15, \geq 20$ points) and percentage change from baseline ( $\geq 30, \geq 50, \geq 70 \%$ ) to days 14,42 , and $84(27,28)$. For all the response thresholds analyzed, a higher percentage of participants in OPUS-2 and OPUS-3 achieved EDS reduction with lifitegrast $v$ s. placebo (Figures 4 and 5) (27).

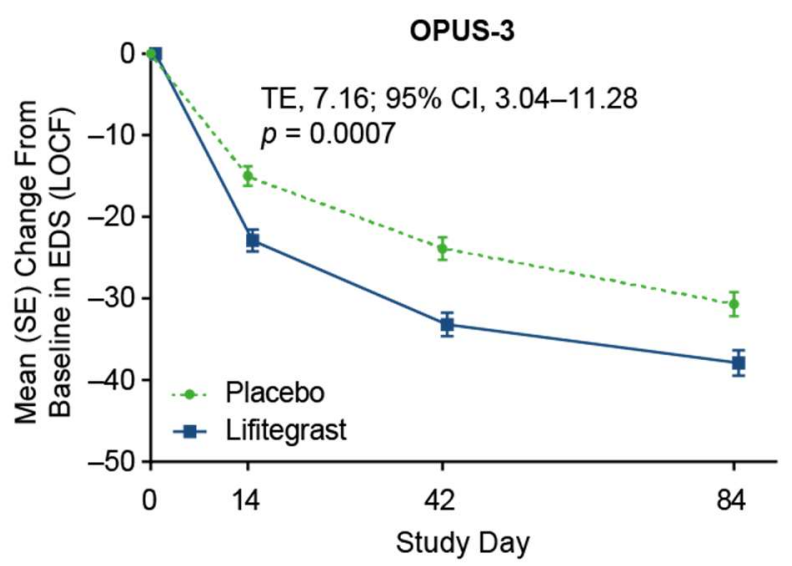

Figure 3. Lifitegrast significantly improved dry eye disease symptoms as assessed by change in EDS (visual analog scale; $0-100$ scale; $0=$ no discomfort) from baseline to days 14, 42, and 84, vs. placebo, in the OPUS-2 and OPUS-3 trials. EDS, eye dryness score; LOCF, last observation carried forward; TE, treatment effect. OPUS-2: placebo, $n=360$; lifitegrast, $n=358$; OPUS-3: placebo, $n=356$; lifitegrast, $n=355$. OPUS-2 figure reproduced from Tauber J, et al. Lifitegrast ophthalmic solution $5.0 \%$ versus placebo for treatment of dry eye disease. Ophthalmology, 2015; 122:2423-2431, DOI: 10.1016/j.ophtha.2015.08.001 (23). Licensed under CC BY-NC-ND 4.0 (https://creativecommons.org/licenses/by-ncnd/4.0). OPUS-3 figure reproduced from Holland EJ, et al. Lifitegrast for the treatment of dry eye disease. Ophthalmology, 2017; 124:53-60, DOI: 10.1016/j.ophtha.2016.09.025 (24). Licensed under CC BY-NC-ND 4.0 (https://creativecommons.org/licenses/by-nc-nd/4.0). 
OPUS-2

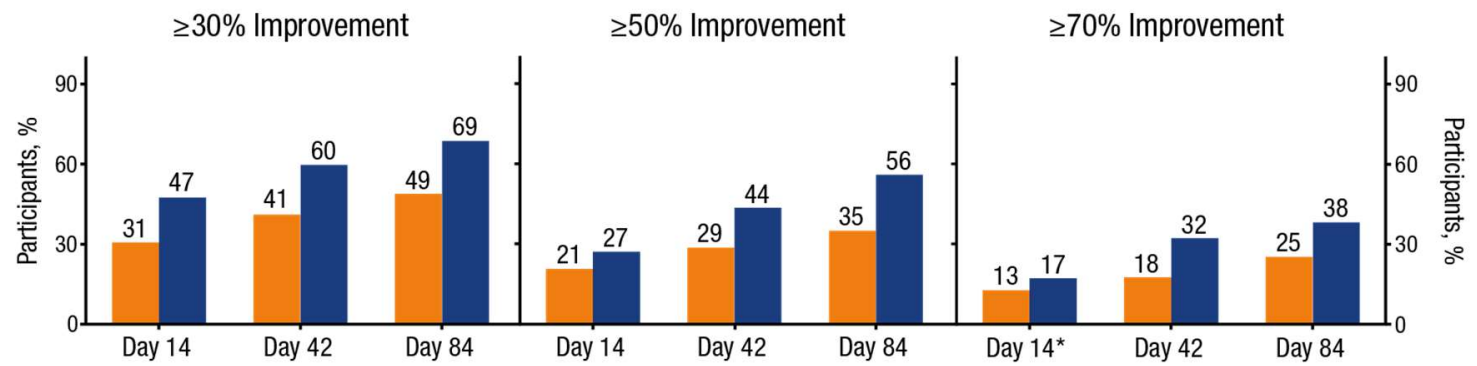

OPUS-3

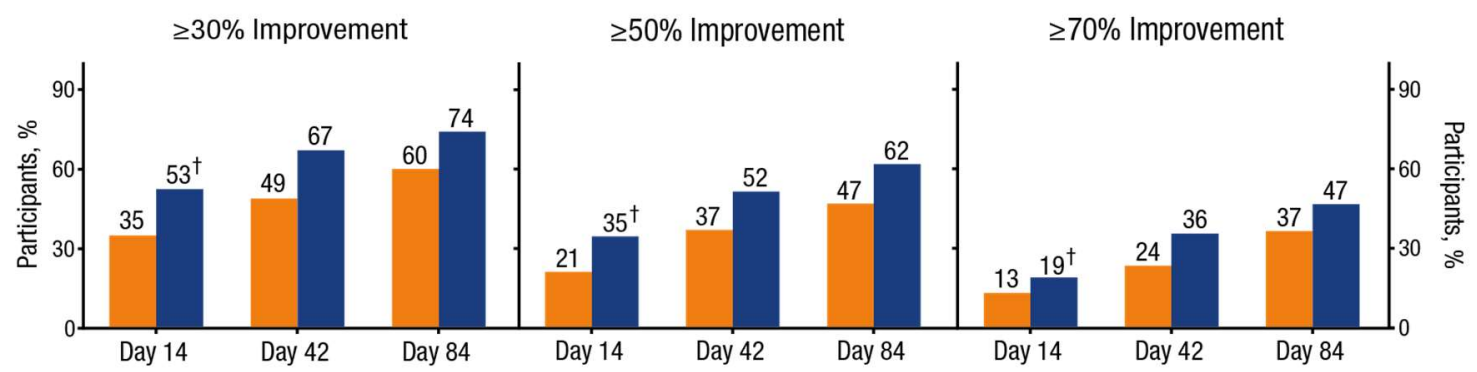

Figure 4. Responder analysis, percentage change from baseline in eye dryness score (EDS; visual analog scale; 0-100 scale; $0=$ no discomfort, $100=$ maximal discomfort). Participants treated with lifitegrast had greater improvement in EDS vs. placebo in the OPUS-2 and OPUS- 3 trials. OPUS-2: placebo, $n=360$; lifitegrast, $n=358$; OPUS-3: placebo, $n=353$; lifitegrast, $n=353$. All $p<0.05 .{ }^{*} p=0.088 .{ }^{\dagger} \mathrm{n}=352$.

\section{OPUS-2}

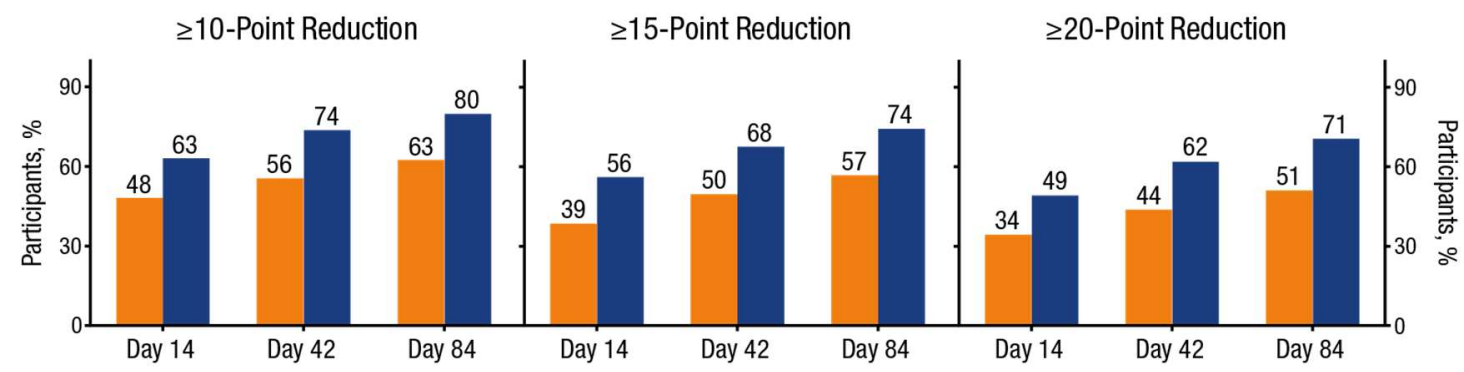

\section{OPUS-3}

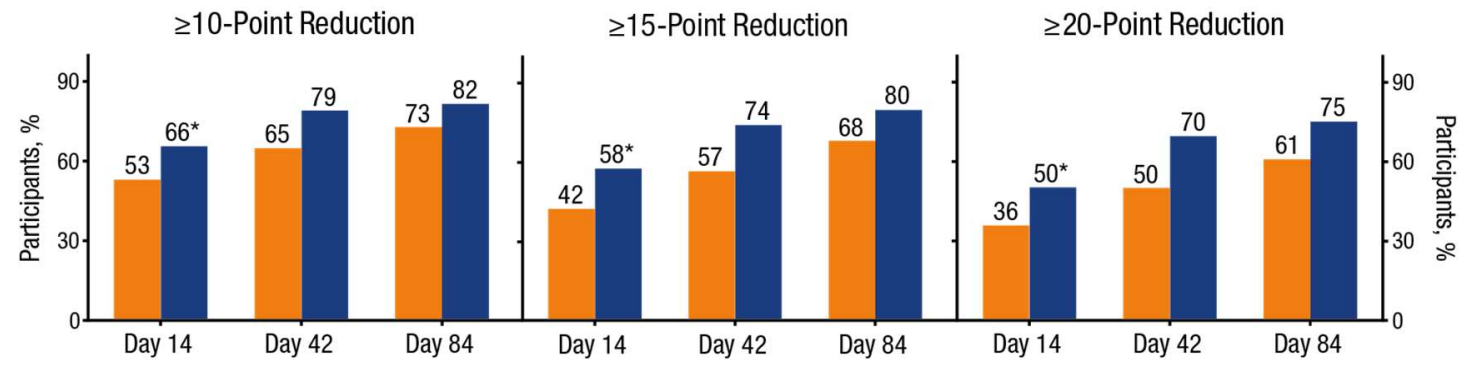

Figure 5. Responder analysis, points change from baseline in eye dryness score (EDS; visual analog scale; $0-100$ scale; $0=$ no discomfort, $100=$ maximal discomfort). Participants treated with lifitegrast had greater improvement in EDS vs. placebo in the OPUS-2 and OPUS-3 trials. OPUS-2: placebo, $\mathrm{n}=360$; lifitegrast, $\mathrm{n}=358$; OPUS-3: placebo, $\mathrm{n}=353$; lifitegrast, $\mathrm{n}=353$. All $p<0.01 .{ }^{*}=352$. 
In the trials before OPUS-2, symptoms were also evaluated on a visual-related function subscale of a symptom scale $(0-4$ scale). The visual-related function subscale showed improvement with lifitegrast in the phase 2 trial, but no significant change was observed in OPUS-1 (15).

Signs of DED were assessed by corneal fluorescein staining of the inferior corneal region (Figure 6) in all of the 12-week trials. Corneal fluorescein staining is observed when the surface epithelial cells are damaged and desiccated. Inferior corneal staining score (ICSS, 0-4 scale) showed significant improvement from baseline with lifitegrast vs. placebo in 3 trials (phase 2, OPUS-1, and OPUS-3) $(15,24)$, but not in the OPUS-2 trial (23).

Pooled safety data from all 5 trials show that lifitegrast was generally well tolerated. No serious ocular treatment-emergent adverse events (TEAEs) were observed (29). Severity of TEAEs was mostly mild or moderate (29). Discontinuations due to TEAEs were infrequent (placebo, 31/1177 [2.6\%]; lifitegrast, 90/1287 [7.0\%]) (29). Most common side effects $(>5 \%)$ were instillation site pain/irritation/reaction and dysgeusia (a temporary sense of altered taste, most commonly a bitter or metallic taste in the mouth) (29).

Data from the 1-year SONATA study confirmed the long-term safety profile of lifitegrast (25). There were no serious ocular TEAEs, and although there was a higher proportion of ocular TEAEs in the lifitegrast group $(53.6 \%$ reported $\geq 1$ TEAE) compared with those receiving placebo (34.2\%), most of these adverse events were mildly or moderately severe and seemed to be transient (resolved in a few minutes). Over one-third of the participants reported using artificial tears (an overthe-counter treatment for dry eye relief). Artificial tear use was reported by a lower proportion of those receiving lifitegrast compared with those on placebo $(32.8 \%$ vs. $43.9 \%)$. Over the course of 1 year, there was a numerical decrease in artificial tear users in the lifitegrast group, and an increase in the placebo group. This suggests that lifitegrast treatment may reduce the need for artificial tears.

The significant improvement in both signs and symptoms of DED in these trials suggest that lifitegrast might also have a beneficial effect on disease progression.

\section{WHAT CAN BE EXPECTED IN THE FUTURE?}

DED is a highly prevalent condition that affects the vision of up to $50 \%$ of the population globally. It is important to maintain awareness of this chronic condition and to initiate timely use of appropriate therapies to target the inherent ocular surface inflammation seen in DED. Lifitegrast is a promising treatment for DED, with a rapid onset of action, and proven efficacy and tolerability in treating both symptoms and signs of DED. Several other drugs are currently in development to treat DED. These include novel formulations of ophthalmic cyclosporine (e.g., nanomicellar formulation, OTX-101, ClinicalTrials.gov identifiers: NCT02845674, NCT02688556, and NCT02254265;
A

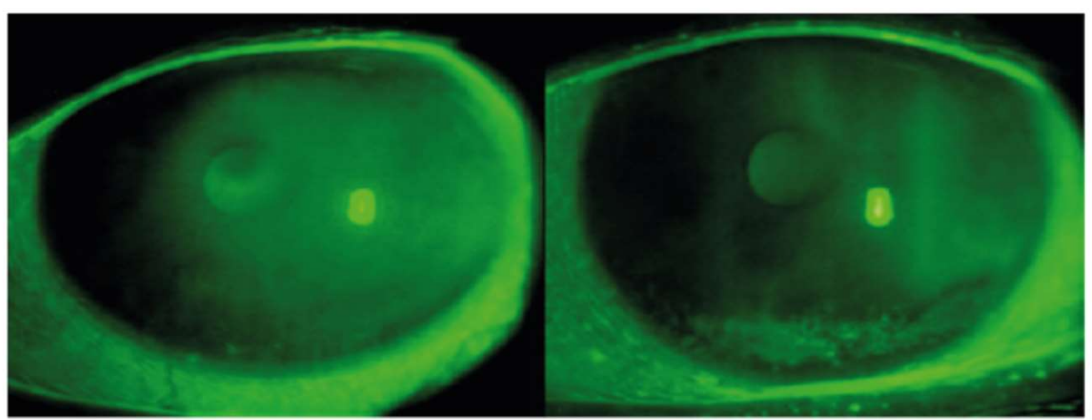

B

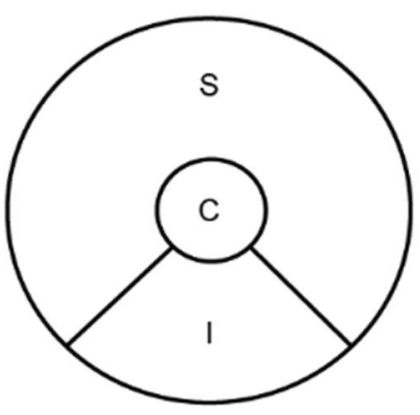

Figure 6. Corneal fluorescein staining for diagnosis of dry eye disease (DED). (A) A representative case of a patient with DED showing corneal fluorescein staining before (left) and after (right) $2 \mathrm{~h}$ of exposure to desiccating stress. (B) A schematic of the corneal regions. C, central region (central one-third of cornea, $4 \mathrm{~mm}$ ); I, inferior region; $\mathrm{S}$, superior region. Corneal fluorescein scoring scale: none, $0=$ no staining; trace, $1=$ few/rare punctate lesions; mild, $2=$ discrete and countable lesions; moderate, $3=$ lesions too numerous to count but not coalescent; severe, $4=$ coalescent. Corneal fluorescein staining images reprinted from the Am J Ophthalmol, Vol 157(4), López-Miguel A, et al, Dry Eye Exacerbation in Patients Exposed to Desiccating Stress under Controlled Environmental Conditions, pages 788-98, 2014, DOI: 10.1016/j.ajo.2014.01.001, with permission from Elsevier (33). 
water-free, excipient-based CyclASol, (30)), ophthalmic corticosteroids (e.g., nanoparticle-based loteprednol etabonate, KPI-121 (31)), and synthetic thymosin $\beta 4$ (32) that treat DED by addressing the underlying inflammation. It is expected that some of these will be approved, thereby expanding the available treatment options for DED.

\section{ABBREVIATIONS}

CAE, controlled adverse environment; CANDEES, Canada Dry Eye Epidemiology Study; DED, dry eye disease; DEWS, Dry Eye Workshop; EDS, eye dryness score; ICAM-1, intercellular adhesion molecule; IL-2, interleukin 2; LFA-1, lymphocyte function-associated antigen 1; TEAE, treatmentemergent adverse event.

\section{COMPETING INTERESTS}

Clara C. Chan has received research support from Allergan, Bausch \& Lomb, and TearLab, and has been a consultant for Alcon, Allergan, Bausch \& Lomb, Santen, Shire PLC, and TearScience. C. Lisa Prokopich has been on speaker bureaus for or consulted with Alcon, Allergan, Bausch \& Lomb, Innova, Santen, and Shire PLC.

\section{FUNDING AND ACKNOWLEDGMENTS}

The studies reviewed in this manuscript were sponsored by SARcode Bioscience (now a wholly owned subsidiary of Shire PLC) and Shire Development LLC. The authors thank Ira Probodh, $\mathrm{PhD}$, of Excel Scientific Solutions, who provided medical writing assistance, funded by SARcode Bioscience, a fully owned company of Shire PLC.

\section{REFERENCES}

1. Craig JP, Nichols KK, Akpek EK, Caffery B, Dua HS, Joo CK, et al. TFOS DEWS II definition and classification report. Ocul Surf, 2017; 15:276-283.

2. Schiffman RM, Walt JG, Jacobsen G, Doyle JJ, Lebovics G, Sumner W. Utility assessment among patients with dry eye disease. Ophthalmology, 2003; 110:1412-1419.

3. Buchholz P, Steeds CS, Stern LS, Wiederkehr DP, Doyle JJ, Katz LM, et al. Utility assessment to measure the impact of dry eye disease. Ocul Surf, $2006 ; 4: 155-161$.
4. Stapleton F, Alves M, Bunya VY, Jalbert I, Lekhanont K, Malet F, et al. TFOS DEWS II epidemiology report. Ocul Surf, 2017; 15:334-365.

5. Doughty MJ, Fonn D, Richter D, Simpson T, Caffery B, Gordon K. A patient questionnaire approach to estimating the prevalence of dry eye symptoms in patients presenting to optometric practices across Canada. Optom Vis Sci, 1997; 74:624-631.

6. Chan C, Caffery B, Srinivasan S, Fischer A, Cappadocia D, Siffel C, et al. Prevalence of dry eye disease in Canada: a population-based survey. Paper presented at: American Society of Cataract and Refractive Surgery Annual Meeting; April 13-17, 2018; Washington, DC, USA.

7. Bron AJ, de Paiva CS, Chauhan SK, Bonini S, Gabison EE, Jain S, et al. TFOS DEWS II pathophysiology report. Ocul Surf, 2017; 15:438510.

8. Jackson WB. Management of dysfunctional tear syndrome: a Canadian consensus. Can J Ophthalmol, 2009; 44:385-394.

9. Prokopich CL, Bitton E, Caffery B, Cunningham DN, Karpecki PM, Webber A, et al. Screening, diagnosis and management of dry eye disease: practical guidelines for Canadian optometrists. Can J Optom, 2014; 76:1-31.

10. Jones L, Downie LE, Korb D, Benitez-Del-Castillo JM, Dana R, Deng SX, et al. TFOS DEWS II management and therapy report. Ocul Surf, 2017; 15:575-628.

11. Jacobs DS. Diagnosis and treatment of ocular pain: the ophthalmologist's perspective. Curr Ophthalmol Rep, 2017; 5:271-275.

12. Belmonte C, Nichols JJ, Cox SM, Brock JA, Begley $\mathrm{CG}$, Bereiter DA, et al. TFOS DEWS II pain and sensation report. Ocul Surf, 2017; 15:404-437.

13. Lienert JP, Tarko L, Uchino M, Christen WG, Schaumberg DA. Long-term natural history of dry eye disease from the patient's perspective. Ophthalmology, 2016; 123:425-433.

14. Rao SN. Topical cyclosporine $0.05 \%$ for the prevention of dry eye disease progression. J Ocul Pharmacol Ther, 2010; 26:157-164.

15. Holland EJ, Whitley WO, Sall K, Lane SS, Raychaudhuri A, Zhang SY, et al. Lifitegrast clinical efficacy for treatment of signs and symptoms of dry eye disease across three randomized controlled trials. Curr Med Res Opin, 2016; 32:1759-1765.

16. Pflugfelder SC, Stern M, Zhang S, Shojaei A. LFA 1/ ICAM-1 interaction as a therapeutic target in dry eye disease. J Ocul Pharmacol Ther, 2017; 33:5-12.

17. Perez VL, Pflugfelder SC, Zhang S, Shojaei A, Haque R. Lifitegrast, a novel integrin antagonist for treatment of dry eye disease. Ocul Surf, 2016; 14:207-215.

18. Chung JK, Spencer E, Hunt M, McCauley T, Welty D. Ocular distribution and pharmacokinetics of 
lifitegrast in pigmented rabbits and mass balance in beagle dogs. J Ocul Pharmacol Ther, 2018; 34:224232.

19. Zhong M, Gadek TR, Bui M, Shen W, Burnier J, Barr $\mathrm{KJ}$, et al. Discovery and development of potent LFA 1/ICAM-1 antagonist SAR 1118 as an ophthalmic solution for treating dry eye. ACS Med Chem Lett, 2012; 3:203-6.

20. Semba CP, Swearingen D, Smith VL, Newman MS, O'Neill CA, Burnier JP, et al. Safety and pharmacokinetics of a novel lymphocyte functionassociated antigen-1 antagonist ophthalmic solution (SAR 1118) in healthy adults. J Ocul Pharmacol Ther, 2011; 27:99-104.

21. Semba CP, Torkildsen GL, Lonsdale JD, McLaurin EB, Geffin JA, Mundorf TK, et al. A phase 2 randomized, double-masked, placebo-controlled study of a novel integrin antagonist (SAR 1118) for the treatment of dry eye. Am J Ophthalmol, 2012; 153:1050-1060.e1.

22. Sheppard JD, Torkildsen GL, Lonsdale JD, D'Ambrosio FA, Jr., McLaurin EB, Eiferman RA, et al; OPUS-1 Study Group. Lifitegrast ophthalmic solution $5.0 \%$ for treatment of dry eye disease: results of the OPUS-1 phase 3 study. Ophthalmology, 2014; 121:475-483.

23. Tauber J, Karpecki P, Latkany R, Luchs J, Martel J, Sall K, et al; OPUS-2 Investigators. Lifitegrast ophthalmic solution $5.0 \%$ versus placebo for treatment of dry eye disease: results of the randomized phase III OPUS-2 study. Ophthalmology, 2015; 122:2423-2431.

24. Holland EJ, Luchs J, Karpecki PM, Nichols KK, Jackson MA, Sall K, et al. Lifitegrast for the treatment of dry eye disease: results of a phase III, randomized, double-masked, placebo-controlled trial (OPUS-3). Ophthalmology, 2017; 124:53-60.

25. Donnenfeld ED, Karpecki PM, Majmudar PA, Nichols KK, Raychaudhuri A, Roy M, et al. Safety of lifitegrast ophthalmic solution $5.0 \%$ in patients with dry eye disease: a 1-year, multicenter, randomized, placebo-controlled study. Cornea, 2016; 35:741-748.

26. Novack GD, Asbell P, Barabino S, Bergamini MVW, Ciolino JB, Foulks GN, et al. TFOS DEWS II clinical trial design report. Ocul Surf, 2017; 15:629-649.
27. Holland EJ, Messmer EM, Baudouin C, Donnenfeld ED, Nichols KK, Karpecki PM, et al. Lifitegrast 5.0\% for the treatment of dry eye disease: responder analysis for reductions in eye dryness score in two phase-3 randomized controlled trials. Paper presented at: Deutsche Ophthalmologische Gesellschaft - 115th Congress; September 28-October 1, 2017; Berlin, Germany.

28. Holland EJ, Baudouin C, Nichols KK, Karpecki PM, Hamdani M, Roy M, et al. Lifitegrast 5.0\% for the treatment of dry eye disease: responder analysis for reductions in eye dryness score in two phase 3 randomized controlled trials. Paper presented at: XXXV Congress of the European Society of Cataract and Refractive Surgeons; October 7-11, 2017; Lisbon, Portugal.

29. Nichols KK, Donnenfeld ED, Karpecki PM, Hovanesian JA, Raychaudhuri A, Shojaei A, et al. Safety and tolerability of lifitegrast ophthalmic solution 5.0\%: pooled analysis of five randomized controlled trials in dry eye disease. Eur J Ophthalmol, 2018:1120672118791936.

30. Torkildsen GL, Moreira HR, Wirta DL, Lonsdale JD, Ciolino JB, Jentsch G, et al. A clinical phase 2 study to assess efficacy, safety, and tolerability of CyclASol for treatment of dry eye disease. Paper presented at: American Academy of Ophthalmology Annual Meeting; November 11-14, 2017; New Orleans, LA, USA.

31. Holland EJ, Gary N Foulks GN, Brazzell KR. Evaluation of KPI-121, a novel nanoparticle formulation of loteprednol etabonate, in dry eye disease. Paper presented at: American Academy of Ophthalmology Annual Meeting; November 14-17, 2015; Las Vegas, NV, USA.

32. Sosne G, Dunn SP, Kim C. Thymosin $\beta 4$ significantly improves signs and symptoms of severe dry eye in a phase 2 randomized trial. Cornea, 2015; 34:491-496.

33. López-Miguel A, Tesón M, Martín-Montañez V, Enríquez-de-Salamanca A, Stern ME, Calonge M, et al. Dry eye exacerbation in patients exposed to desiccating stress under controlled environmental conditions. Am J Ophthalmol, 2014; 157:788-798.e2. 